\title{
Relative impact of clinical evidence and over-the-counter prescribing on topical antibiotic use for acute infective conjunctivitis
}

\author{
Helen Davis, David Mant, Caroline Scott, Daniel Lasserson and Peter W Rose
}

\begin{abstract}
\section{Background}

Acute infective conjunctivitis is a common presentation in general practice. In 2005, three placebo-controlled clinical trials showed that use of topical antibiotics had a small effect on time to clinical resolution. In the same year, chloramphenicol eye drops were made available for sale over the counter.
\end{abstract}

\section{Aim}

To compare the relative impact of clinical trial evidence and a change to over-the-counter availability on community use of topical chloramphenicol.

\section{Design of study}

Observational study using mainly routinely collected data for England.

\section{Setting}

National prescribing data for England and local data from general practices in Oxfordshire, England.

\section{Method}

Data were collated from three sources: GP prescriptions from the Prescription Pricing Authority, wholesale supply to pharmacists from IMS Health, and an audit of delayed prescribing and non-prescribing from electronic consultation records for acute conjunctivitis, in four general practices.

\section{Results}

The number of general practice prescriptions for topical chloramphenicol fell from 2.3 million in 2004 to 1.9 million in 2007 , a reduction of $15.5 \%$. In contrast, over-the-counter sales by pharmacists have increased steadily. The net effect of these changes has been a $47.8 \%$ increase in total chloramphenicol use during 2005-2007, with 1.1 million additional packs being used in 2007 compared to 2004.

\section{Conclusion}

Making an antibiotic available over the counter increases its use substantially. This is in conflict with the important public health message that antibiotic use needs to be reduced to combat resistance. These findings support the views of the Chief Medical Officer that no more antibiotics should currently be made available over the counter.

Keywords

antibiotics; conjunctivitis; drug prescribing; community pharmacy services.

\section{INTRODUCTION}

Four years ago, in mid-summer 2005, two things happened with the potential to have an impact on the use of topical antibiotics for treating acute infective conjunctivitis in the UK. First, three papers on placebo-controlled clinical trials into the efficacy of topical antibiotic use in acute infective conjunctivitis were published. ${ }^{1-3}$ The authors' own study, in children, showed that while the majority of cases were due to bacterial infection, and antibiotic use increased pathogen eradication, topical antibiotics did little to speed clinical resolution (the median time to resolution in both arms of the trial was 5 days). ${ }^{1}$ The other two community-based trials reported similar findings in studies that included adults. ${ }^{2,3} \mathrm{~A}$ subsequent meta-analysis confirmed that the relative benefit of antibiotics for early cure is small, and eradication of pathogens is not necessary for clinical cure - so two-thirds of cases $(65 \%)$ will resolve within 5 days without antibiotics. ${ }^{4}$ The clinical consensus in response to this evidence was that GPs should not prescribe antibiotics routinely for infective conjunctivitis; instead, treatment should be reserved only for those whose symptoms do not resolve, perhaps most efficiently through the

H Davis, MA, BM BCh, foundation doctor; D Mant, FRCP, FRCGP, professor; C Scott, MRCGP, DCH, DRCOG, academic clinical fellow; D Lasserson, MA, MRCP, MRCGP, clinical lecturer; $P W$ Rose, MD, FRCGP, university lecturer, Department of Primary Health Care, NIHR School of Primary Care Research, University of Oxford, Oxford.

Address for correspondence

Dr Peter Rose, Department of Primary Health Care, NIHR School of Primary Care Research, University of Oxford, Old Road, Headington, Oxford OX3 7LF.

E-mail: peter.rose@dphpc.ox.ac.uk

Submitted: 14 May 2009; Editor's response: 8 June 2009; final acceptance: 23 July 2009.

(CBritish Journal of General Practice 2009; 59: 897-900.

DOI: 10.3399/bjgp09X473132 


\section{How this fits in}

Antibiotic prescribing has previously been shown to decline following the publication of clinical trials that have indicated little benefit in symptom resolution. Patients consult less if there is reduced expectation of a prescription. This study confirms these findings that prescribing of topical antibiotics for acute infective conjunctivitis declined after publication of trial evidence. However, overall topical antibiotic use for acute infective conjunctivitis has risen due to over-the-counter availability. These findings have implications for policymaking decisions on whether to make further antibiotics available over the counter.
December 2007. These data are estimates of total sales. These UK data were converted into data for England alone by multiplying figures by 0.838 , the proportion of the total UK population living in England (UK National Statistics, mid-2006 values).

\section{Local audit data on prescribing behaviour}

Data on delayed prescribing and non-prescribing are not readily abstracted from national computerised databases without patient consent to access individual records, so an in-depth audit was undertaken using a convenience sample of four university-linked practices in Oxfordshire. A search was conducted for all consultations that had taken place for acute conjunctivitis (Read code F4C0) in each year from 2000-2007, and for all prescriptions for topical anti-infective eye preparations (Section 11.3.1 of the British National Formulary). A detailed audit was conducted of all consultations that had taken place for acute conjunctivitis within one pre2005 and one post-2005 year in each practice, by examining the medical notes for each individual consultation. In two practices the chosen pre-2005 year was 2003, but in the other two practices data were collected for 2000 because these practices had taken part in the trial of chloramphenicol use in conjunctivitis which started in 2001; 2007 was used as the post-2005 year in all practices. The medical record for each consultation was reviewed to record the treatment outcome: no prescription, prescription, or delayed prescription. relative effect of these conflicting drivers for chloramphenicol use in England since 2005.

\section{METHOD}

Data on the use of topical chloramphenicol were collated from three sources: the Prescription Pricing Authority, on GP prescriptions used; IMS Health, on wholesale supply to pharmacists of over-the-counter sales; and an audit of four general practices in Oxfordshire on prescribing practice.

\section{GP prescribing}

The Prescription Pricing Authority provided monthly figures of chloramphenicol prescriptions dispensed in England from March 2003 to December 2007 from the ePACT (Electronic Prescribing Analysis and Cost) database, which includes all FP10 prescriptions that have been issued, dispensed, and submitted to pricing authorities for payment. It does not include prescriptions issued by hospitals or dental practitioners.

\section{Over-the-counter sales}

IMS Health provided monthly figures for the number of packs of chloramphenicol sold to pharmacies for sale over the counter in the UK from January 2005 to

\section{Data analysis}

As both wholesale sales and prescription data show considerable variation through the year (peaking in March), 12-month rolling averages were used to display the results graphically.

\section{RESULTS}

The number of general practice prescriptions for topical chloramphenicol dispensed in England was stable (acknowledging the seasonal variation) until 2005. The number of general practice prescriptions for topical chloramphenicol fell from 0.21 million in December 2004 to 0.16 million in December 2007 (the last month data were available), a reduction of $23.2 \%$. Aggregating data over a year, the number of general practice prescriptions for topical chloramphenicol fell from 2.3 million in 2004 to 1.9 million in 2007 , a reduction of $15.5 \%$. The number of GP prescriptions for all topical anti-infective eye preparations fell by a similar amount (13.0\%), suggesting that it is not merely a change in choice of agent that accounts for the decreased chloramphenicol prescribing (Table 1).

The local audit data suggest that the fall may be 
Table 1. Prescriptions dispensed and over-the-counter sales of topical anti-infective eye preparations, in millions, between 2004 and 2007, in England.

\begin{tabular}{|c|c|c|c|c|}
\hline Year & $\begin{array}{l}\text { Total topical anti-infective } \\
\text { eye prescriptions (ePACT) }\end{array}$ & $\begin{array}{l}\text { Topical chloramphenicol } \\
\text { prescriptions (ePACT) }\end{array}$ & $\begin{array}{l}\text { Topical chloramphenicol } \\
\text { over-the-counter sales (IMS Health) }\end{array}$ & $\begin{array}{l}\text { Total topical } \\
\text { chloramphenicol use }\end{array}$ \\
\hline 2004 & 3.22 & 2.30 & - & 2.30 \\
\hline 2005 & 3.04 & 2.31 & 0.68 & 2.99 \\
\hline 2006 & 2.79 & 2.00 & 1.10 & 3.11 \\
\hline 2007 & 2.80 & 1.94 & 1.46 & 3.40 \\
\hline
\end{tabular}

Data are gathered from ePACT and IMS Health, as described in the main text.

due both to a fall in consultations for acute infective conjunctivitis and to an increase in the use of delayed prescriptions. Aggregating data across the four practices, the number of consultations fell from 17.6 per 1000 patients in 2004 to 12.6 per 1000 patients in 2007 , a reduction of $28.5 \%$. The proportion of consultations for which a delayed prescription was issued increased by $14.7 \%$ (from $0.7 \%$ pre-2005 to $15.4 \%$ post-2005), and consultations for which no prescription was issued increased by $14.5 \%$ (from $5.8 \%$ pre-2005 to $20.3 \%$ post-2005). Many of the consultation notes contained statements such as 'Discussed evidence - will return if no better' or 'Discussed evidence but nursery insist on antibiotic drops'.

In contrast, wholesale sales of chloramphenicol for over-the-counter prescribing by pharmacists have increased steadily since it was made available over the counter in June 2005. In August 2007, more topical chloramphenicol was sold over the counter in England than dispensed as NHS FP10 prescriptions. Figure 1 summates the national results for dispensed prescriptions and over-the-counter sales, showing that the net effect of these changes has been a $47.8 \%$ increase in chloramphenicol use during 2005-2007, with 1.1 million additional packs being used in 2007 compared to 2004.

\section{DISCUSSION}

\section{Summary of main findings}

Despite a reduction in dispensed prescriptions of topical chloramphenicol by GPs, the overall use of antibiotics for acute conjunctivitis has risen substantially due to the increased availability of chloramphenicol over the counter. The increased use of no prescribing and delayed prescribing suggests that the fall in dispensed prescriptions does reflect, at least in part, a response by GPs to emerging evidence. However, the fall in consultation rate for this condition may reflect patients bypassing their GP and buying chloramphenicol over the counter.

\section{Strengths and limitations of the study}

The audit data from general practice are restricted to four university-linked teaching practices, two of

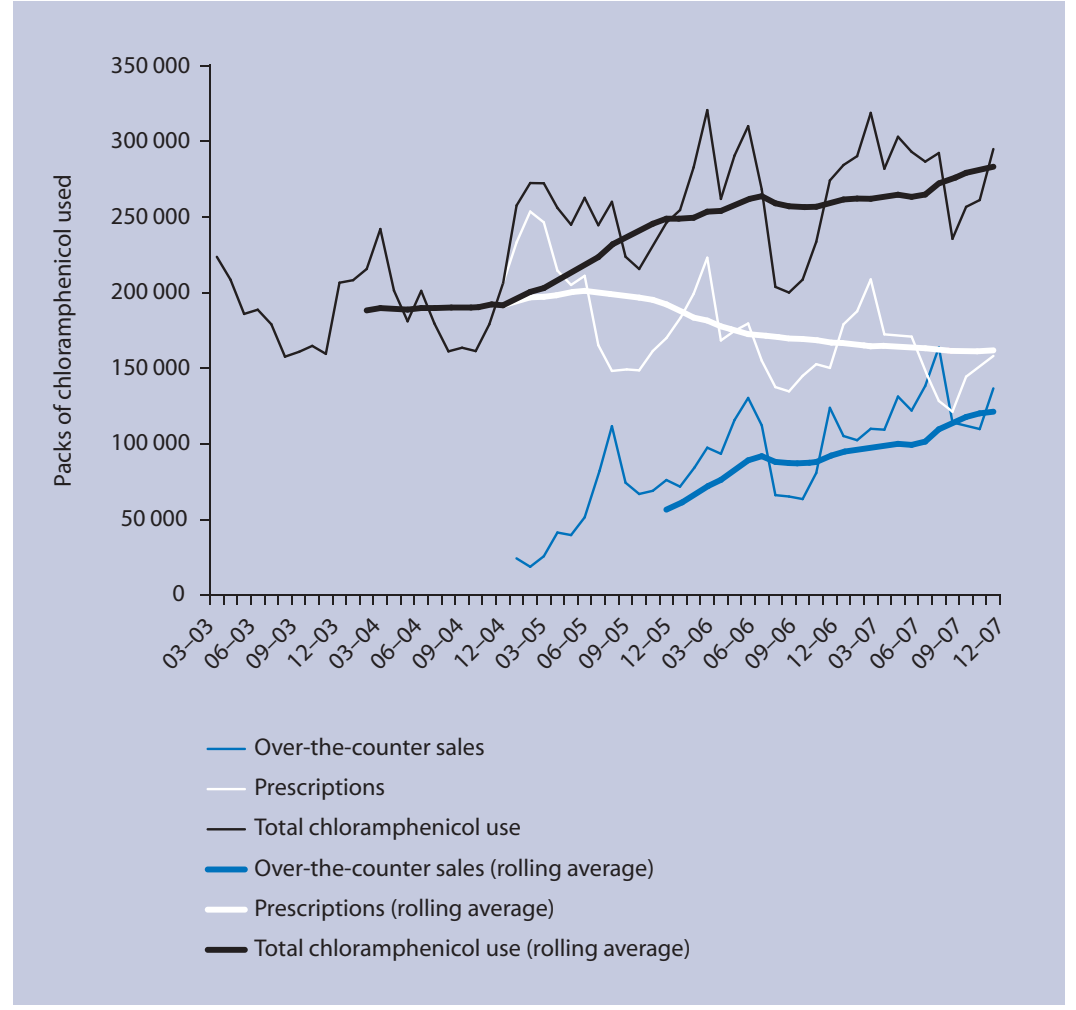

which were actually involved in the conjunctivitis trial. They are likely to be more aware of, and responsive to, the emerging research evidence on this issue than the average practice in the UK. However, these audit data are presented only to try to explain the national trend in dispensed FP10 prescriptions for all practices, which is robust. The data on over-thecounter use is based on sales of topical chloramphenicol to pharmacies; actual sales to customers will necessarily lag behind these figures by the average period for which stocks are held. These data are estimates, extrapolating from pharmacies that supply data to IMS Health to all pharmacies in the UK. There is no way to explore the precision of these estimates but there is no reason to anticipate substantial bias or inaccuracy and they are widely used by industry. The data reported represent consumption trends of the antibiotics and there are no data to determine the appropriateness of prescriptions or over-the-counter sales. No specific
Figure 1. Trend in community use of topical chloramphenicol 2003-2007. 
measurement was made of whether there was any change in prescribing behaviour for topical antibiotics for conditions other than conjunctivitis over the time period studied. It is also possible that the proportion of patients with acute conjunctivitis being seen in hospital emergency departments has increased, and topical chloramphenicol is being prescribed there. It was not possible to access data to measure this.

\section{Comparison with existing literature}

The study audit data suggest that about half of all general practice prescriptions for topical chloramphenicol are issued for acute infective conjunctivitis, so the proportionate fall in prescribing for this specific indication is probably twice that suggested by the overall fall in dispensed prescriptions, assuming that prescribing for other indications has remained constant. This is consistent with reductions in antibiotic prescribing and increase in delayed prescribing for other common infections in children. ${ }^{11}$ It is already known that patients may consult less for conjunctivitis if there is reduced expectation of a prescription, ${ }^{12}$ despite the pressure to prescribe to children to enable school and nursery attendance..$^{13}$ One of the conjunctivitis trials found that intention to re-attend for eye infections fell after patients were given no or delayed antibiotics, from $68 \%$ to about $40 \% .^{3}$ Similarly, prescription rates remained low after a practice policy change to give delayed instead of immediate antibiotics for children with otitis media. ${ }^{14}$

\section{Implications for future research and clinical practice}

GPs appear to have responded to evidence by changing practice. In contrast, pharmacists are selling increasing amounts of chloramphenicol for acute conjunctivitis - does this mean they are unaware of the evidence, interpret it in a different way to doctors, or do not have time to discuss the evidence of modest efficacy with patients? The authors are also aware of individual cases where pharmacists have dispensed for indications other than infective conjunctivitis (once, in the presence of one of the authors as a customer, for a swelling on the eyelid). Increasing availability of medicines empowers patients to manage their own health. However, with the case of antibiotics there must be a balance between individual autonomy and overall public health. Although increasing use of topical chloramphenicol may in itself cause little adverse effect on public health, the authors have deep concerns that it represents the thin end of a very dangerous wedge. Azithromycin is now available over the counter for proven cases of Chlamydia and the MHRA is currently consulting about the change of status of nitrofurantoin. However, the Chief Medical Officer in his 2009 annual report states that 'no further antibiotic classes should be made available without prescription unless there is careful consideration of the potential public health consequences'. ${ }^{15}$

\section{Funding body}

There was no funding for this research, which was undertaken during a student attachment

\section{Ethical approval}

Ethical approval was not required for this research

\section{Competing interests}

The authors have stated that there are none

\section{Acknowledgement}

The Prescription Pricing Authority provided the data on GP prescriptions and IMS Health provided the data on wholesale supplies to pharmacies free of charge.

\section{Discuss this article}

Contribute and read comments about this article on the Discussion Forum: http://www.rcgp.org.uk/bjgp-discuss

\section{REFERENCES}

1. Rose PW, Harnden A, Brueggemann AB, et al. Chloramphenicol treatment for acute infective conjunctivitis in children in primary care: a randomised double-blind placebo-controlled trial. Lancet 2005; 366(9479): 37-43

2. Rietveld RP, ter Riet G, Bindels PJ, et al. The treatment of acute infectious conjunctivitis with fusidic acid: a randomised controlled trial. Br J Gen Pract 2005; 55(521): 924-930.

3. Everitt HA, Little PS, Smith PW. A randomised controlled trial of management strategies for acute infective conjunctivitis in general practice. BMJ 2006; 333(7563): 321.

4. Sheikh A, Hurwitz B. Antibiotics versus placebo for acute bacterial conjunctivitis. Cochrane Database Syst Rev 2006; (2): CD001211.

5. Rose P. Management strategies for acute infective conjunctivitis in primary care: a systematic review. Expert Opin Pharmacother 2007; 8(12): 1903-1921.

6. MHRA. Press release, 8 June 2005. Antibiotic eye drops available over the counter.

http://www.mhra.gov.uk/NewsCentre/Pressreleases/CON2014984 (accessed 18 Aug 2009).

7. MHRA. Legal status and reclassification. http://www.mhra.gov.uk/Howweregulate/Medicines/Licensingofmedici nes/Legalstatusandreclassification/index.htm (accessed 18 Aug 2009).

8. Sharland M. The use of antibacterials in children: a report of the Specialist Advisory Committee on Antimicrobial Resistance (SACAR) Paediatric Subgroup. J Antimicrob Chemother 2007; 60(suppl 1): 115-126.

9. Priest P, Yudkin P, McNulty C, Mant D. Antibacterial prescribing and antibacterial resistance in English general practice: cross sectional study. BMJ 2001; 323(7320): 1037-1041.

10. Chung A, Perera R, Brueggemann A, et al. Effect of antibiotic prescribing on antibiotic resistance in individual children in primary care: a prospective study. BMJ 2007; 335(7617): 429.

11. Sharland M, Kendall H, Yeates D, et al. Antibiotic prescribing in general practice and hospital admissions for peritonsillar abscess, mastoiditis, and rheumatic fever in children: time trend analysis. BMJ 2005. 331(7512): 328-329.

12. Everitt $\mathrm{H}$, Kumar S, Little P. A qualitative study of patients' perceptions of acute infective conjunctivitis. Br J Gen Pract 2003; 53(486): 36-41.

13. Rose PW, Ziebland S, Harnden A, et al. Why do general practitioners prescribe antibiotics for acute infective conjunctivitis in children? Qualitative interviews with GPs and a questionnaire survey of parents and teachers. Fam Pract 2006; 23(2): 226-232.

14. Cates C. An evidence based approach to reducing antibiotic use in children with acute otitis media: controlled before and after study. BMJ 1999; 318(7185): 715-716.

15. Donaldson L. 150 years of the Annual Report of the Chief Medical Officer: On the state of public health 2008. London: Department of Health Annual Reports, 2009.

http://www.dh.gov.uk/en/Publicationsandstatistics/Publications/Annua IReports/DH_096206 (accessed 18 Aug 2009). 